\title{
X-RAY COMPUTED TOMOGRAPHY IMAGE-BASED MESO-SCALE DYNAMIC FRACTURE OF CONCRETE UNDER COMPRESSION: MONTE CARLO SIMULATIONS
}

\author{
YUJIE HUANG ${ }^{\dagger^{*}}$, ZHENJUN YANG $^{\dagger \dagger, \dagger}$ AND GUOHUA LIU ${ }^{\dagger}$ \\ ${ }^{\dagger}$ College of Civil Engineering and Architecture, Zhejiang University, Hangzhou, China \\ ${ }^{\dagger \dagger}$ Research Centre for Low Impact Buildings, Coventry University, UK \\ e-mail: mpcyujie@126.com
}

Key words: Dynamic fracture, Meso-scale modelling of concrete, In-situ X-ray computed tomography, 2D Image based modelling, Damaged plasticity model

\begin{abstract}
Meso-scale two-dimensional (2D) finite element models are developed for fracture modelling in concrete based on images from an in-situ micro-scale X-ray Computed Tomography test. The concrete damaged plasticity model is employed to capture the dynamic fracture mechanical behavior of concrete under uniaxial compression. By Monte Carlo simulations, the present study statistically focuses on the effects of loading rate as well as heterogeneity of mesostructure on the macroscopic mechanical properties and the failure patterns of concrete. The calculated dynamic increase factors are in good agreement with experimental results and empirical predictions. Cracks in high strain rate cases are more likely to connect voids and form dense damage network within the whole specimen. It is also suggested that the internal defects should be minimized for optimal material design especially when structures are exposed to high strain rates.
\end{abstract}

\section{INTRODUCTION}

Understanding the dynamic properties of concrete material is paramount for better designs and safety assessment of concrete structures under dynamic loadings such as impact and blast at a wide spectrum of strain rates from $10^{-8}$ to $10^{3} \mathrm{~s}^{-1}[1,2]$. Many studies [1-8] reveal that the concrete compressive strength increases with the strain rate, and the strength improvement can be described by the compressive dynamic increase factor (CDIF) defined as the ratio of dynamic-to-static strength. It may be inappropriate to directly use the CDIF obtained from macroscopic dynamic tests as a material property of concrete, because it includes both the material effects and the structural effects [6-8].

As an alternative to dynamic experiments, meso-scale numerical modeling can provide more insights with explicit meso-features including the shapes, volume fractions and distributions of multiple phases (aggregates, mortar, interfacial transition zones (ITZs) and voids) [6-8]. These meso-scale features, which are obscurely considered as material effects by macroscopic dynamic tests or numerical simulations assuming homogeneous material behavior, now become structural in mesomodelling.

Recently, digital images, acquired by optical devices such as cameras, microscopes and X-ray computed tomography (XCT) scanners, have been used to generate micro/meso-scale numerical models [9-13]. These image-based models take into account realistic sizes, shapes, volume fractions and distributions of multiple phases and thus result 
in more accurate and more representative mechanical responses. The simulated damage and fracture processes can even be directly validated by in-situ XCT tests of concrete samples [10,13]. However, no image-based micro/meso-scale models have been used to simulate damage and fracture of concrete under dynamic loadings, to the best knowledge of the authors.

This study aims at a better understanding of the dynamic mechanical behavior of concrete under compression by extensive Monte Carlo simulations of 2D meso-scale concrete models based on micro-scale XCT images. The concrete damaged plasticity (CDP) model in ABAQUS is used in this paper to simulate complicated damage initiation and evolution.

\section{METHODOLOIGY}

\subsection{XCT-image based model}

The detailed image-based modelling method can be referred to our recent papers $[12,13]$, and only the essential information is briefly presented here. The $2 \mathrm{D}$ images are obtained from the in-situ X-ray Computed Tomography test [11], and have 372 pixels of $0.1 \mathrm{~mm}$ in both directions. An image slice is first processed with grey-value based segmentation to label pixels with material identity of aggregates, mortar or initial cracks/voids, resulting in a ternary image. Then an image compression process is carried out to reach a balance between morphology accuracy and computational efficiency. Figure 1a-c shows three examples of an image slice with pixels of $0.1 \mathrm{~mm}, 0.2 \mathrm{~mm}$ and $0.4 \mathrm{~mm}$, respectively. A set of 93 image slices with resolution of $0.4 \mathrm{~mm}$ is obtained and used in the following Monte Carlo simulations. Next, the mortar pixels connected with aggregate pixels are identified to model the weaker aggregate-mortar interfaces, namely the interfacial transition zone (ITZ).

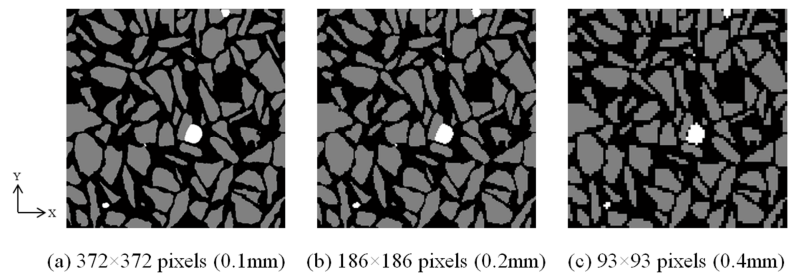

Figure 1: Image processing and compression [13]

\subsection{Concrete damaged plasticity model}

The concrete damaged plasticity (CDP) model was first proposed by Lubliner et al. [14] for monotonic loading, and it was developed later by Lee and Fenves [15] to consider the dynamic and cyclic loading conditions. This continuum plastic model assumes that the main failure mechanisms of the concrete are cracking in tension and crushing in compression. The CDP model has been included in ABAQUS and has proved capable of modelling concrete dynamic mechanical behavior [13,16].

In this study, the CDP model is used to model both the mortar and ITZs. The aggregates are assumed elastic without damage in this study. The main mechanical parameters used in the following simulations are listed in Table 1.

Table 1: Main material properties

\begin{tabular}{cccc}
\hline & Mortar & ITZ & Aggregate \\
\hline $\begin{array}{c}\text { Mass density } \\
\left(\mathrm{kg} / \mathrm{m}^{3}\right)\end{array}$ & $2.2 \times 10^{3}$ & $2.2 \times 10^{3}$ & $2.5 \times 10^{3}$ \\
$\begin{array}{c}\text { Young's } \\
\text { modulus (GPa) }\end{array}$ & 20 & 15 & 50 \\
Poisson's ratio & 0.2 & 0.2 & 0.2 \\
$\quad \begin{array}{c}\text { Tensile } \\
\text { strength (MPa) } \\
\text { Compressive } \\
\text { strength (MPa) } \\
\text { Fracture }\end{array}$ & 2.8 & 2.1 & - \\
energy (N/mm) & 0.04 & 0.02 & - \\
\hline
\end{tabular}

It should be noted that, in the present study, no strain-rate terms are incorporated in the CDP model. In other words the constitutive material properties of meso-phases are 
considered as strain-rate independent as in [8], and the dynamic strength enhancement in the model is attributed to structural effects including the meso-structure and the lateral inertial confinement.

\section{2D MONTE CARLO SIMULATIONS}

The uniaxial compression tests are simulated using the XCT-image based 2D models under seven loading conditions with strain rate $30 \times 10^{-6}$ (static), $10^{-4}, 10^{-3}, 10^{-2}, 0.2$, 2 and $10 \mathrm{~s}^{-1}$, respectively. The load is applied by prescribing horizontal displacements ( $x$ direction) to all nodes on the left face, while the opposite face is fixed horizontally with free lateral deformation. The loading condition is thus end friction free, as in [8]. Seven Monte Carlo simulations (MCSs) are conducted, under each loading condition for all 93 image slices with $0.4 \mathrm{~mm}$ pixels or element size (Figure 1c). The dynamic load-carrying capacity, crack pattern and void effect are statistically investigated based on the MCSs results.

\subsection{Damage and fracture processes under different strain rates}

Figure 2a-e shows the damage distributions of the same 2D model after failure under different strain rates. The very different pictures demonstrate that the strain rate makes significant differences to the failure pattern. At relatively low strain rate, the damage zones are localised into a few inclined macro-cracks passing the biggest voids. When the strain rate gets higher, more and more macro-cracks appear, forming a complicated network. Additionally, the macro-crack network under high strain rate tends to connect all the voids within the whole specimen. The specimen is almost pulverized at failure when the strain rate reaches $10 \mathrm{~s}^{-1}$. This simulated behavior is consistent with other numerical studies [7] and experimental investigations [17].

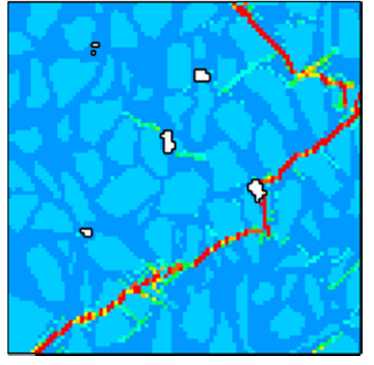

(a) $8 \&=30 \times 10^{-6} \mathrm{~s}^{-1}$ (static)

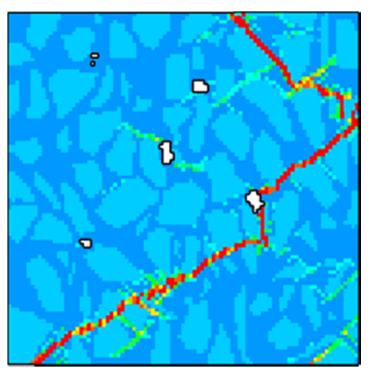

(b) $8 \&=1 \times 10^{-3} \mathrm{~s}^{-1}$

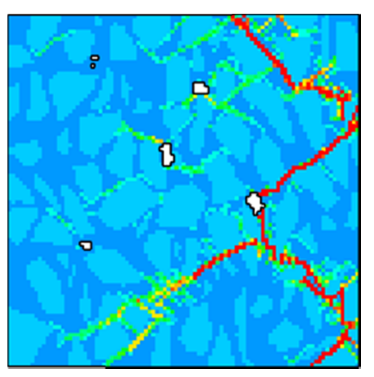

(c) $\& \&=1 \times 10^{-2} \mathrm{~s}^{-1}$

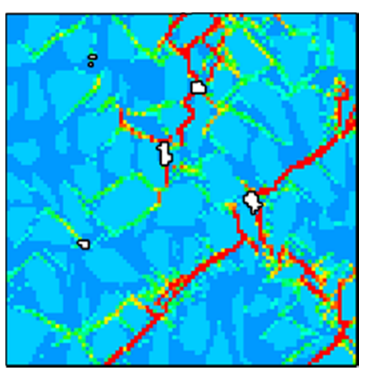

(d) $8 \&=2 \mathrm{~s}^{-1}$

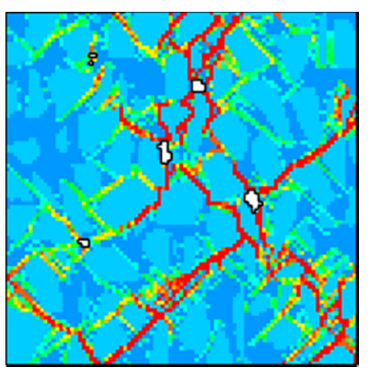

(e) $8 \&=10 \mathrm{~s}^{-1}$

Figure 2: Damage distribution at failure under different strain rates 


\subsection{Dynamic compressive strengths from MCSs}

Figure 3a-d shows the stress-strain curves from the MCSs under four strain rates as examples. The mean curve and its peak stress are also shown for each loading case. For each MCS, there is a small difference in the initial slope of the curves, indicating the slight influence of the multiphasic distribution on the elastic behavior. However, significant scatters in the peak stress and the post-peak softening part can be seen for all the strain rates, caused by the random distribution and different fractions of multiple phases in the 93 images (or samples).

Table 2 summarises the mean and the standard deviation of the peak stress and CDIF of the 93 image-based models for the seven strain rates, respectively. The peak stress is defined as the dynamic compressive strength herein. For each sample, the CDIF is calculated as the ratio between the dynamic compressive strength and the compressive strength under static loading. It can be seen that higher strain rates lead to higher mean peak stresses as well as slightly higher standard deviation (SD) of peak stresses (or lower structural reliability against impact). It can also be seen that the CDIF becomes more sensitive to higher strain rate. The peak stress of each mean curve is also presented in Table 2.

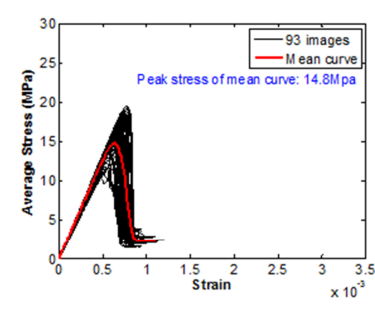

(a) $\dot{\varepsilon}=30 \times 10^{-6} \mathrm{~s}^{-1}$ (static)

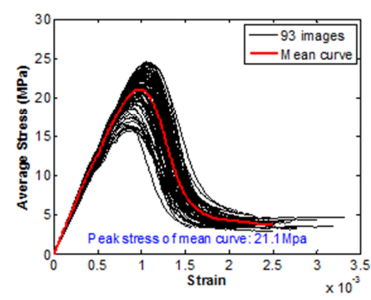

(c) $\dot{\varepsilon}=2 \mathrm{~s}^{-1}$

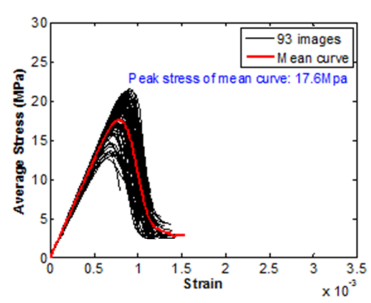

(b) $\dot{\varepsilon}=1 \times 10^{-2} \mathrm{~s}^{-1}$

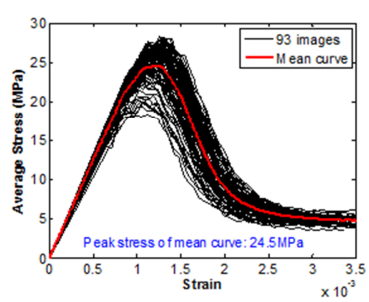

(d) $\dot{\varepsilon}=10 \mathrm{~s}^{-1}$
Figure 3: Stress-strain curves from MCSs under different strain rates
Table 2: Statistics of Monte Carlo simulation results

\begin{tabular}{cccccccc}
\hline $\begin{array}{c}\text { Strain } \\
\text { rate } \\
\&\left(\mathrm{~s}^{-1}\right)\end{array}$ & $\begin{array}{c}30 \times \\
10^{-6}\end{array}$ & $\begin{array}{c}1 \times \\
10^{-4}\end{array}$ & $\begin{array}{c}1 \times \\
10^{-3}\end{array}$ & 0.01 & 0.2 & 2 & 10 \\
\hline $\begin{array}{c}\text { Mean of } \\
\text { peak } \\
\text { stress } \\
\text { (MPa) }\end{array}$ & 16.0 & 16.1 & 16.7 & 18.1 & 19.5 & 21.4 & 25.1 \\
$\begin{array}{c}\text { SD of } \\
\text { peak } \\
\text { stress }\end{array}$ & 2.11 & 2.12 & 2.14 & 2.18 & 2.20 & 2.25 & 2.30 \\
$\begin{array}{c}\text { (MPa) } \\
\text { Mean of } \\
\text { CDIF }\end{array}$ & - & 1.02 & 1.05 & 1.15 & 1.23 & 1.36 & 1.60 \\
$\begin{array}{c}\text { SD of } \\
\text { CDIF }\end{array}$ & - & 0.01 & 0.01 & 0.04 & 0.05 & 0.07 & 0.10 \\
\hline
\end{tabular}

The results of the CDIF in Table 2 are then curve-fitted using the least square method (with correlation factor $R^{2}=0.96$ ) as

$$
\begin{gathered}
\mathrm{CDIF}=1+0.34 \& \mathrm{~d}^{0.28} \pm \mathrm{SD} \\
\mathrm{SD}=0.07 \& \mathrm{~d}^{0.21}
\end{gathered}
$$

Figure 4 compares the simulated CDIFstrain rate relation with the experimental data $[1,3]$ and the two empirical curves [5,18]. The simulation results are well within the documented data, indicating that the XCTimage based models are capable of simulating the dynamic responses of concrete. In addition, the results from MCS include the statistical information that is more valuable for reliability-based structural design than a single curve from deterministic studies.

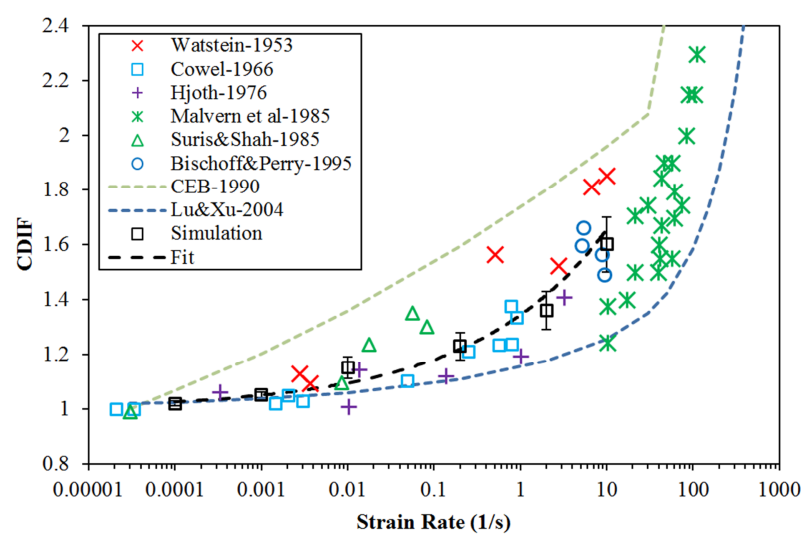

Figure 4: Comparison of CDIFs from MCSs with test data and other empirical formulations 
Moreover, as the DIF and strain rate-related terms are not input in the material constitutive laws, and the loading is friction free, it is reasonable to infer that the dynamic enhancement of strength mainly comes from the lateral inertial confinement (i.e. the Poisson's effect) and the heterogeneous mesostructure in the models.

\subsection{Effects of void area fraction}

Voids are widely known to affect mechanical properties of concrete-like materials [12-13]. However, quantification of the effects of voids on the dynamic behavior of concrete has not been reported, to the best knowledge of the authors. Figure 5a-d plots the void area fraction (VAF)-compressive strength relation predicted from the 93 imagebased models for different strain rates, and there exists an inversely proportionate relation between the VAF and the dynamic strength, which has also been noted by the authors for static studies [12]. This is because more voids reduce the effective area of resistance.

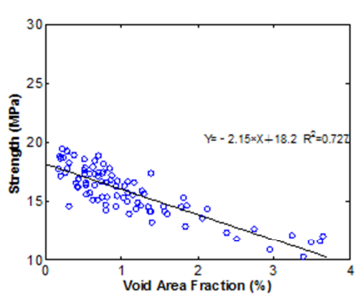

(a) $\varepsilon=30 \times 10^{-6} \mathrm{~s}^{-1}$ (static)

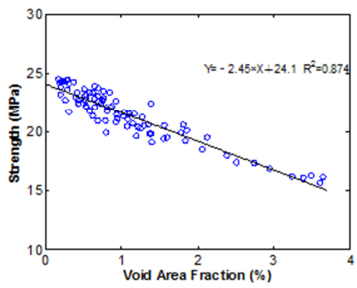

(c) $\dot{\varepsilon}=2 \mathrm{~s}^{-1}$

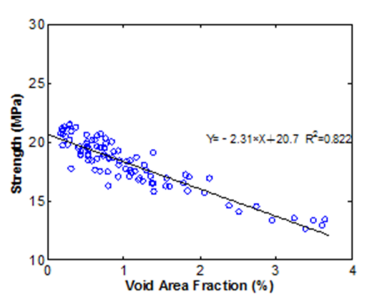

(b) $\dot{\varepsilon}=1 \times 10^{-2} \mathrm{~s}^{-1}$

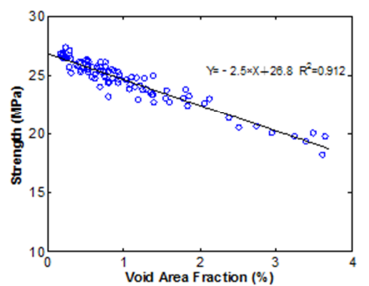

(d) $\dot{\varepsilon}=10 \mathrm{~s}^{-1}$
Figure 5: Void area fraction (VAF)-compressive strength relation under different strain rates

Table 3 lists the coefficients $a$ and $b$ of the straight lines $(y=a x+b)$ from least-square curve-fitting based on all the MCS results, to describe the VAF-compressive strength relation. Two correlation factors are also given: $R^{2}$ represents determination coefficient and $r$ the correlation coefficient while $R^{2}=r^{2}$. It can be noted that $|a|$ increases as the strain rate increases, indicating the reduction rate of strength with the VAF is higher for higher strain rates. Moreover, $|r|$ is higher as the strain rate increases, indicating a higher level of correlation between $\mathrm{VAF}$ and the dynamic strength at higher strain rates. This suggests that the dynamic strength is more sensitive to the void contents at higher strain rates and thus the internal defects should be minimized for optimal material design especially under dynamic loadings of high strain rates.

Table 3: Curve-fitting and correlation parameters based on Monte Carlo simulations

\begin{tabular}{cccccccc}
\hline$\&$ & $30 \times$ & $1 \times$ & $1 \times$ & 0.01 & 0.2 & 2 & 10 \\
$\left(\mathrm{~s}^{-1}\right)$ & $10^{-6}$ & $10^{-4}$ & $10^{-3}$ & & \\
\hline$a$ & -2.15 & -2.18 & -2.24 & -2.31 & -2.37 & -2.45 & -2.50 \\
$b$ & 18.2 & 18.4 & 19.7 & 20.7 & 22.1 & 24.1 & 26.8 \\
$R^{2}$ & 0.73 & 0.75 & 0.78 & 0.82 & 0.85 & 0.87 & 0.91 \\
$r$ & -0.85 & -0.86 & -0.88 & 0.04 & -0.91 & -0.94 & -0.96
\end{tabular}

\section{CONCLUSIONS}

In this study, the dynamic damage and fracture behavior of concrete under compression with strain rate up to $10 \mathrm{~s}^{-1}$ has been studied by extensive Monte Carlo simulations of 2D meso-scale concrete models based on high-resolution XCT images, to elucidate the complicated dynamic behavior of concrete. The strain rate has profound effects on the damage evolution, the failure pattern and the dynamic strength. The lateral inertia confinement and the meso-structures are the main mechanisms for the dynamic strength enhancements. The proposed CDIF-strain rate relation provides standard deviations/errors that are important for reliability-based structural assessment (using Gaussian possibility density function) and design but are unavailable from conventional deterministic studies. The dynamic compressive behavior under higher strain rates is found more 
sensitive to the void fraction.

\section{ACKNOWLEDGEMENTS}

This research is funded by National Natural Science Foundations of China (No.11390361), National Basic Research Program of China (973 Program Project 2013CB035901), and Zhejiang Provincial Natural Science Foundation of China (No. LR14E080002).

\section{REFERENCES}

[1] Bischoff PH, Perry SH. 1991. Compressive behaviour of concrete at high strain rates. Materials and structures 24(6): 425-450.

[2] Hentz S, Donzé FV, Daudeville, L. 2004. Discrete element modelling of concrete submitted to dynamic loading at high strain rates. Computers and structures 82(29): 2509-2524.

[3] Grote DL, Park SW, Zhou M. 2001. Dynamic behavior of concrete at high strain rates and pressures: I. experimental characterization. International Journal of Impact Engineering 25(9): 869-886.

[4] Li QM, Meng H. 2003. About the dynamic strength enhancement of concrete-like materials in a split Hopkinson pressure bar test. International Journal of solids and structures 40(2): 343-360.

[5] Comite Euro-International du Beton. 1993. CEB-FIP model code 1990. UK: Redwood books, Wiltshire.

[6] Cusatis G. 2011. Strain-rate effects on concrete behavior. International Journal of Impact Engineering 38(4): 162-170.

[7] Zhou XQ, Hao H. 2008. Modelling of compressive behaviour of concrete-like materials at high strain rate. International Journal of Solids and Structures 45(17): 4648-4661.

[8] Song Z, Lu Y. 2012. Mesoscopic analysis of concrete under excessively high strain rate compression and implications on interpretation of test data. International Journal of Impact Engineering 46: 41-55.

[9] Man HK, van Mier JGM. 2008. Size effect on strength and fracture energy for numerical concrete with realistic aggregate shapes. International Journal of Fracture 154(1-2): 61-72.

[10] Asahina D, Landis EN, Bolander JE. 2011. Modeling of phase interfaces during precritical crack growth in concrete. Cement and Concrete Composites 33(9): 966-977.

[11] Yang ZJ, Ren WY, Mostafavi M, Mcdonald SA, Marrow TJ. 2013. Characterisation of 3D fracture evolution in concrete using in-situ x-ray computed tomography testing and digital volume correlation. VIII International Conference on Fracture Mechanics of Concrete and Concrete Structures. Toledo, pp. 236-42.

[12] Ren WY, Yang ZJ, Sharma R, Zhang CH, Withers PJ. 2015. Two-dimensional X-ray CT image based meso-scale fracture modelling of concrete. Engineering Fracture Mechanics 133: 24-39.

[13] Huang YJ, Yang ZJ, Ren WY, Liu GH, Zhang CZ. 2015. 3D In-situ XCT Image Based Meso-scale Fracture Modelling and Validation of Concrete Using Voxel Hexahedron Meshing and Damage Plasticity Model. International Journal of Solids and Structures 67-68: 340-352.

[14] Lubliner J, Oliver J, Oller S, Oñate E. 1989. A plastic-damage model for concrete. International Journal of Solids and Structures 25(3): 299-326.

[15] Lee J, Fenves GL. 1998. Plastic-damage model for cyclic loading of concrete structures. Journal of Engineering Mechanics 124(8): 892-900.

[16] Chen GM, Teng JG, Chen JF. 2010. Finite-element modeling of intermediate crack debonding in FRP-plated RC beams. Journal of Composites for Construction 15(3): 339-353.

[17] Chen X, Wu S, Zhou J. 2013. Experimental and modeling study of dynamic mechanical properties of cement paste, mortar and concrete. Construction and Building Materials 47: 419-430.

[18] Lu Y, Xu K. 2004. Modelling of dynamic behaviour of concrete materials under blast loading. International Journal of Solids and Structures 41(1): 131-143. 